\title{
In reply: Monitoring recovery from neuromuscular block using acceleromyography at the trapezius muscle: problems that must be considered
}

\author{
Stefan Soltesz, MD • Christian Stark, MD • Karl G. Noé, MD • Michael Anapolski, MD • \\ Thomas Mencke, MD
}

Received: 23 July 2016/Accepted: 2 August 2016/Published online: 9 August 2016

(C) Canadian Anesthesiologists' Society 2016

\section{To the Editor,}

We would like to reply to the methodological concerns raised by Dr. Unterbuchner. ${ }^{1}$ Among them was the issue of randomization, which is usually required to diminish differences caused by inter-individual variations. As our measurements were always performed simultaneously in the same patient, however, the two "groups" were absolutely identical with regard to demographic data or concomitant diseases. Thus, randomization was not necessary to achieve results without bias.

With regard to the neuromuscular measurements, we adhered as strictly as possible to the Good Clinical Research Practice guidelines (GRCP) published by Fuchs-Buder et $a l .{ }^{2}$ According to these guidelines, the use of an elastic preload may indeed decrease variability at the adductor pollicis, although its use is still not considered mandatory. Furthermore, for assessment at the trapezius muscle itself, it was obviously not feasible. As for the stimulus duration of $0.1 \mathrm{msec}$ that we used, admittedly a stimulus duration of $0.2 \mathrm{msec}$ is the recommended standard. Our choice of $0.1 \mathrm{msec}$ may have decreased the current necessary for achieving supramaximum stimulation, ${ }^{2}$ but it did not influence our results. We also

S. Soltesz, MD $(\bowtie) \cdot$ C. Stark, MD · T. Mencke, MD

Department of Anesthesia and Intensive Care Medicine, KKH

Dormagen, Dormagen, Germany

e-mail: Stefan.soltesz@kkh-ne.de

K. G. Noé, MD

Department Obstetrics and Gynecology, KKH Dormagen, Dormagen, Germany

M. Anapolski, MD

Department of Gynecology, KKH Dormagen, Dormagen, Germany did not observe any cases of impaired supramaximum stimulation at either measurement site.

The recommended time period for signal stabilization is two to five minutes, but it may take 5 to $20 \mathrm{~min}$. In light of this discrepancy, the ten-minute period in our investigation was likely sufficiently long. Any cases with substantial drift during this period were excluded. All analyzed cases had a stable signal prior to injection of rocuronium. We agree with Dr. Unterbuchner that this design might have led to a higherthan-ideal number of excluded subjects. Nevertheless, we believe that the data of the included patients are valid.

Additionally, Dr. Unterbuchner correctly states that analyzing a normalized train of four (TOF) ratio would lead to even more pronounced differences between the measurement sites. The GCRP guidelines recommend that an uncorrected (not normalized) TOF ratio be reported. ${ }^{2}$ Therefore, we decided to present the original data, particularly as our study was a methods comparison.

\section{Conflicts of interest None declared.}

Editorial responsibility This submission was handled by Dr. Hilary P. Grocott, Editor-in-Chief, Canadian Journal of Anesthesia.

\section{References}

1. Unterbuchner $C$. Monitoring recovery from neuromuscular block using acceleromyography at the trapezius muscle: problems that must be considered. Can J Anesth 2016; 63: this issue. DOI: 10. 1007/s12630-016-0715-x.

2. Fuchs-Buder T, Claudius C, Skovgaard LT, et al. Good clinical research practice in pharmacodynamic studies of neuromuscular blocking agents II: the Stockholm revision. Acta Anaesthesiol Scand 2007; 51: 789-808. 